\title{
EFFECT OF LIQUID VISCOSITY ON CAVITATION DAMAGE BASED ON ANALYSIS OF EROSION PARTICLES
}

\author{
B. Saleh ${ }^{1}$, A. Ezz El-Deen ${ }^{1}$, and S. M. Ahmed ${ }^{2}$ \\ 1 Mechanical Engineering Dept., Faculty of Engineering, Assiut \\ University, Assiut, Egypt \\ E-mails: bahaa_saleh69@yahoo.com,ahmed_ezz@yahoo.com \\ 2 Mechanical Engineering Dep., Faculty of Engineering, Majmaah \\ University, North Riyadh, Kingdom of Saudi Arabia, \\ E-mail: shemy2007@yahoo.com
}

(Received January 20 2011, Accepted March 26, 2011)

\begin{abstract}
The effect of viscosity on the wear particles produced by vibratory cavitation erosion tests on Al-99.92 in distilled water and glycerol-water solutions was analyzed. Scanning electron microscope images of wear particles during incubation period were obtained. The surface topography examination revealed that the erosion particles were formed by fatigue. The particles removed from glycerol-water solutions differ from that formed in distilled water, where fatigue striations formed on the particle surface for glycerol-water solutions and not formed for distilled water. Therefore, the stress produced by cavitation bubbles decreases with increase of viscosity.
\end{abstract}

KEYWORDS: cavitation damage, erosion particles, glycerol-water mixture, viscosity, particle morphology.

\section{INTRODUCTION}

Cavitation behavior and subsequent damage to material are obviously affected by liquid properties such as density, compressibility, vapor pressure, viscosity and surface tension [1-3]. With regard to the liquid viscosity, Plesset [4] measured the cavitation erosion rates in the organic liquids formamide, ethanol, acetone and glycerol and compared them with the rate in distilled water to get erosion ratio (ER). It has been found that glycerol with its extremely high viscosity has an ER exceeded in this group only by water. Therefore, it is concluded that the effect of viscosity is insignificant. However, Plesset result were obtained using totally different liquids so that the erosion reductions observed were not solely due to the changes of viscosity. Plesset measured also the damage rates for solutions of these organic liquids in water and all these solutions showed a monotonic decrease in going from pure water to pure organic liquid except glycerol. The water-glycerol solutions go through a minimum damage rate for a solution with molecular ratio of glycerol to water of approximately 1 to 1 . Iwai et al. [5] studied the cavitation erosion of mild steel in aqueous glycol solutions. They observed that mass loss decreases but localized intense erosion occurs with increasing percentage of glycol, which is remarkable at more than $60 \%$ glycol. Eurata [6] studied the cavitation erosion in various fluids and he reported that for glycerol solution, the erosion decreases as the concentration increases. It is also reported that when 
concentration is increased above $90 \%$, the erosion data becomes unstable. On the other hand the effect of liquid properties on ultrasound intensity and cavitational activity has been studied by Majumdar et al. [7]. They concluded that the viscosity of the liquid is an important parameter affecting the intensity of ultrasound. The effect of fluid properties on the bubble dynamics has been extensively studied and reviewed in the Refs [1-3]. Recently, Liu et al studied experimentally the collapse of a laser-induced cavitation bubbles near a rigid boundary and its dependence on liquid viscosity by fiber-coupling optical beam deflection. They conduced that the liquid jet is a dominant factor in cavitation damage and can be modified by liquid viscosity. They added that a high viscosity reduces the liquid-jet impact force and cavitation erosion markedly. Therefore, the effect of liquid viscosity on cavitation damage is still vague. Examination of the eroded surfaces and dislodged particles would lead to better understanding of the liquid viscosity effect on cavitation damage. Furthermore, particle analysis can provide direct and early information on cavitation erosion occurring in closed systems so that remedial action can be taken before the break down point is reached.

The objective of the present study is to identify the shape of erosion particles and clarify their morphological features with change in liquid viscosity based on information acquired by particle analysis and eroded surface topography.

\section{EXPERIMENTAL PROCEDURE}

Cavitation erosion tests were performed using an ultrasonic vibratory facility conforming to ASTM standard G32-06 [8] with the stationary specimen method. A schematic diagram of the rig is shown in Fig.1. The peak-to-peak amplitude and the vibratory frequency used were $50 \mu \mathrm{m}$ and $19.5 \pm 0.5 \mathrm{kHz}$, respectively. The stationary specimen sample that was held below the horn tip of $12.7 \mathrm{~mm}$ diameter has an area of $25 \times 25 \mathrm{~mm}^{2}$ and a thickness of $3 \mathrm{~mm}$. The separation distance, L between the stationary specimen and the horn tip was initially adjusted using a dial gage and maintained at a value of $0.8 \mathrm{~mm}$ to obtain significant value of erosion rate [9].

In order to change the viscosity of the test liquids, mixtures of glycerin and distilled water of various concentrations at room temperature of $30^{\circ} \mathrm{C}$ were employed. The variations of viscosity, surface tension and density as a function of the concentration of glycerol are shown in Table 1. The values of water are shown at $0 \mathrm{vol} \%$. With increasing concentration, the viscosity of the mixture increases. The change in the surface tension with concentration is small.

The stationary specimens were made of Al-99.92 whose damage is easily detectable because of its low wear resistance. Specimens were cut from a single block of Al-99.92 to ensure metallurgical uniformity. Since the surface roughness plays an important role in developing erosion and material removal [10-12], therefore, the specimen's working faces were polished with $\mathrm{SiC}$ paper successively down to 2000 grit. Before and after each test, the specimens were rinsed in acetone and dried in air. Then the specimens were weighed with $100 \mathrm{~g} \pm 0.1 \mathrm{mg}$ balance.

The specimen and the end of the stepped horn were immersed in $1200 \mathrm{ml}$ open beaker having $700 \mathrm{ml}$ of glycerol-water mixture. Since the test liquid temperature markedly affects the degree of erosion $[13,14]$ the test solution temperature in the beaker was kept constant at $30 \pm 2{ }^{\circ} \mathrm{C}$ by circulating cooling water as shown in Fig. 1 . 


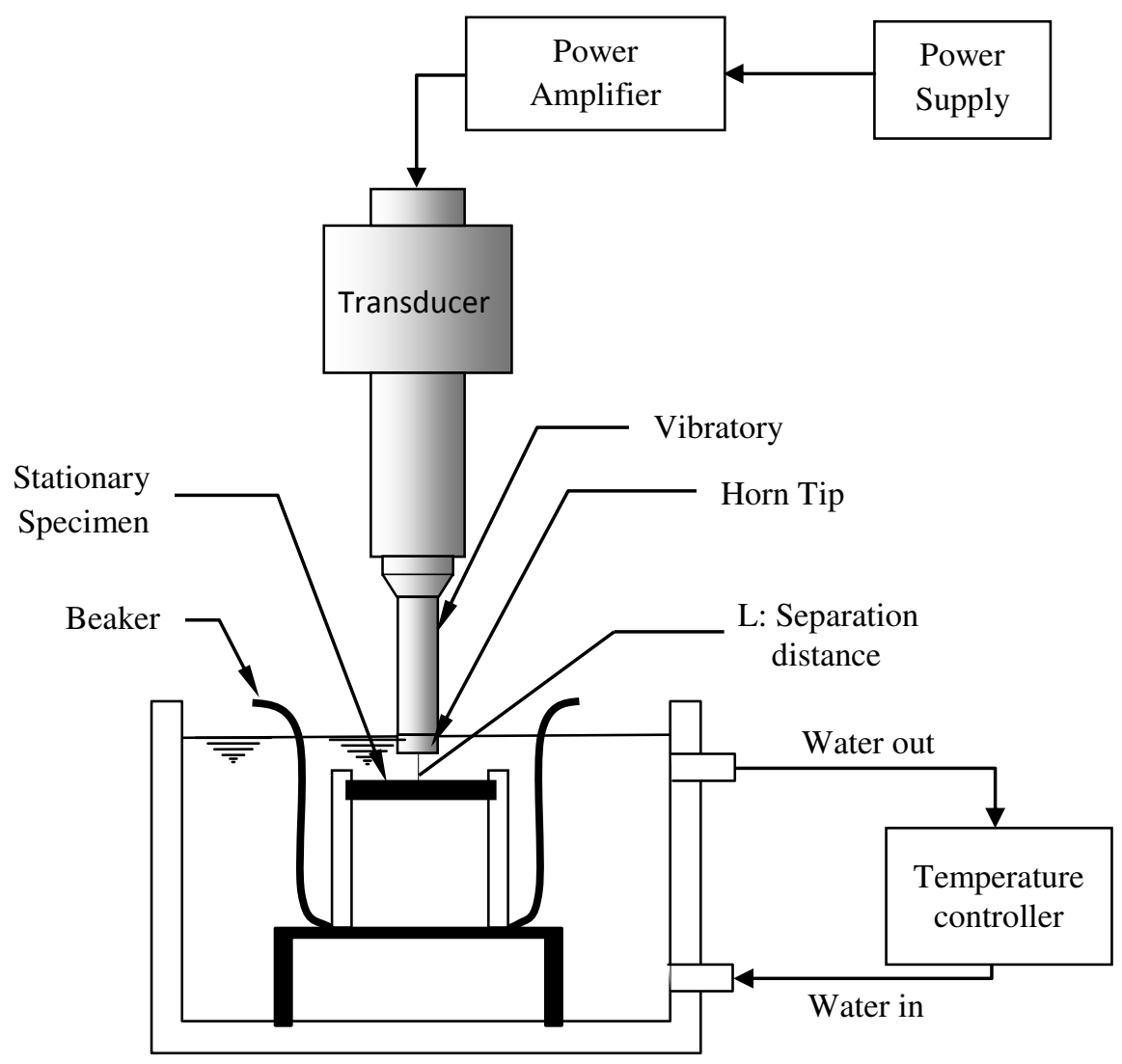

Fig. 1 Schematic view of test apparatus

Table 1: Viscosity, surface tension and density of glycerol-water mixtures at $30{ }^{\circ} \mathrm{C}$

\begin{tabular}{|c|c|c|c|}
\hline $\begin{array}{c}\text { Vol. \% } \\
\text { glycerol/water }\end{array}$ & $\begin{array}{c}\text { Viscosity, } \\
\mathrm{cSt}\end{array}$ & $\begin{array}{c}\text { Surface tension, } \\
\text { dyne/cm }\end{array}$ & $\begin{array}{c}\text { Density, } \\
\mathrm{kg} / \mathrm{m}^{3}\end{array}$ \\
\hline 0 & 0.810 & 71.18 & 995.67 \\
\hline 54.76 & 10.078 & 70.79 & 1156.53 \\
\hline 67.80 & 20.279 & 64.56 & 1186.50 \\
\hline 72.07 & 34.200 & 64.88 & 1192.47 \\
\hline 73.64 & 40.172 & 64.96 & 1193.90 \\
\hline 77.07 & 52.76 & 69.62 & 1204.3 \\
\hline
\end{tabular}

Preliminary tests showed that the temperature of the solution film rose rapidly regardless of the constant temperature in the beaker. This temperature was measured for a maximum interval test time with a thermocouple inserted in the center of test piece. It was found for a 5 min (maximum interval test time) and for mixture of high viscosity $(52 \mathrm{cSt})$ in the present work, that the film temperature exceeded the controlled temperature of beaker by $15^{\circ} \mathrm{C}$.

Therefore, a stirrer was used within the beaker which made the film temperature not exceeding the bulk temperature by more than $4{ }^{\circ} \mathrm{C}$. The effect of stirrer 
on the dynamics of bubbles has been reasonably neglected for each test specimen experienced the same effect. The viscosity of solution was tested at regular intervals during vibration to find any variation in viscosity due to degradation. It was found that a reduction of $10.6 \%$ in the viscosity occurred after $5 \mathrm{~min}$ in the case of solution having a viscosity of $52.76 \mathrm{cSt}$. Then the viscosity did not change with time. The erosion particles were collected from the test solution by a plastic filter with a pore diameter of $0.45 \mu \mathrm{m}[15,16]$. The filter paper has a porous cellulose nitrate membrane. The erosion particles on the filter were transferred to a brass stub covered with carbon tape.

The feature of the eroded surface and the particle morphology were examined using scanning electron microscopy (JEOL JSM 5400), while the chemical composition of particles was determined by $\mathrm{X}$-ray emission microanalysis.

\section{RESULTS AND DISCUSSION}

\subsection{Cavitation erosion test results}

Figure 2 shows the cumulative mass losses of specimens tested in the solution of different viscosities and as function of time. The erosion curves can be divided into two stages, namely, an incubation period, where the mass loss is very small - without a detectable weight loss - and a damage period where the cumulative mass loss increases with exposure time. Increasing the viscosity increases the incubation period. The incubation period for the viscosity of 10 to $40 \mathrm{cSt}$ is nearly the same. However for viscosity of $52.8 \mathrm{cSt}$ the incubation period was less than that for viscosity of 10-40 cSt. For the damage period, the effect of viscosity in these results had a pronounced effect on mass loss rate where the mass loss rates were less than that for distilled water of 1 cs viscosity. The decrease in the intensity of cavitations can be explained in the light of bubble dynamic behavior. At increasing viscosity the growth and collapse of a cavitations bubble is retarded, due to the higher drag force of the liquid. At a certain viscosity the drag force becomes too high and the bubble has insufficient pressure to grow to critical radius. If this radius is not reached, no collapse will occur [17], and consequently the cavitation intensity decreases with increasing viscosity. For solution having a viscosity of $52.8 \mathrm{cSt}$ the intensity of cavitation increases and becomes larger than that for $10 \mathrm{cSt}$ viscosity. This can be, partially interpreted by locally raising of liquid temperature. Then other mechanisms will operate.

\subsection{Particle analysis}

The topography of the detached particles is an inverse replica of the cavitation erosion surface. Therefore, surface examination of wear particles is clearly a reliable technique for predicting the cavitation erosion mechanism as stated by Roylance and Raadnui [18]. SEM Images representing typical wear particles for $99.92 \mathrm{Al}$ cavitating in distilled and glycerol-water mixtures are shown in Figs. 3 and 4. The particles observed in these figures are for incubation period. It is worth noting that these microphotographs are of different magnifications. It can be seen that the particle shape is irregular for all test solutions; cavitation tests generated both large and small-sized wear particles. The large particles often exceeded $200 \mu \mathrm{m}$ in major dimension. The small particles were often in the order of micrometer in major dimension. Despite a significant size difference, both large and small particles showed very similar 
morphological characteristics in all the test solutions, which proved that they were formed by a single mechanism. All the generated particles for the test solutions are laminar particles and showed signs of plastic deformation and traces of the virgin surface, as shown by the arrows labeled V in Figs. 3 and 4, which may be distinguished by polishing traces. It is easy to observe the crack propagation, secondary cracks and ridge shown on the surface of all particles presented in Figs 3 and 4. All the particle marks aforementioned give evidence that all particles were removed by fatigue for all test solutions. These results confirm the previous results reported in Refs $[15,16]$ that the dominant mode of cavitation failure for ductile material is fatigue failure.

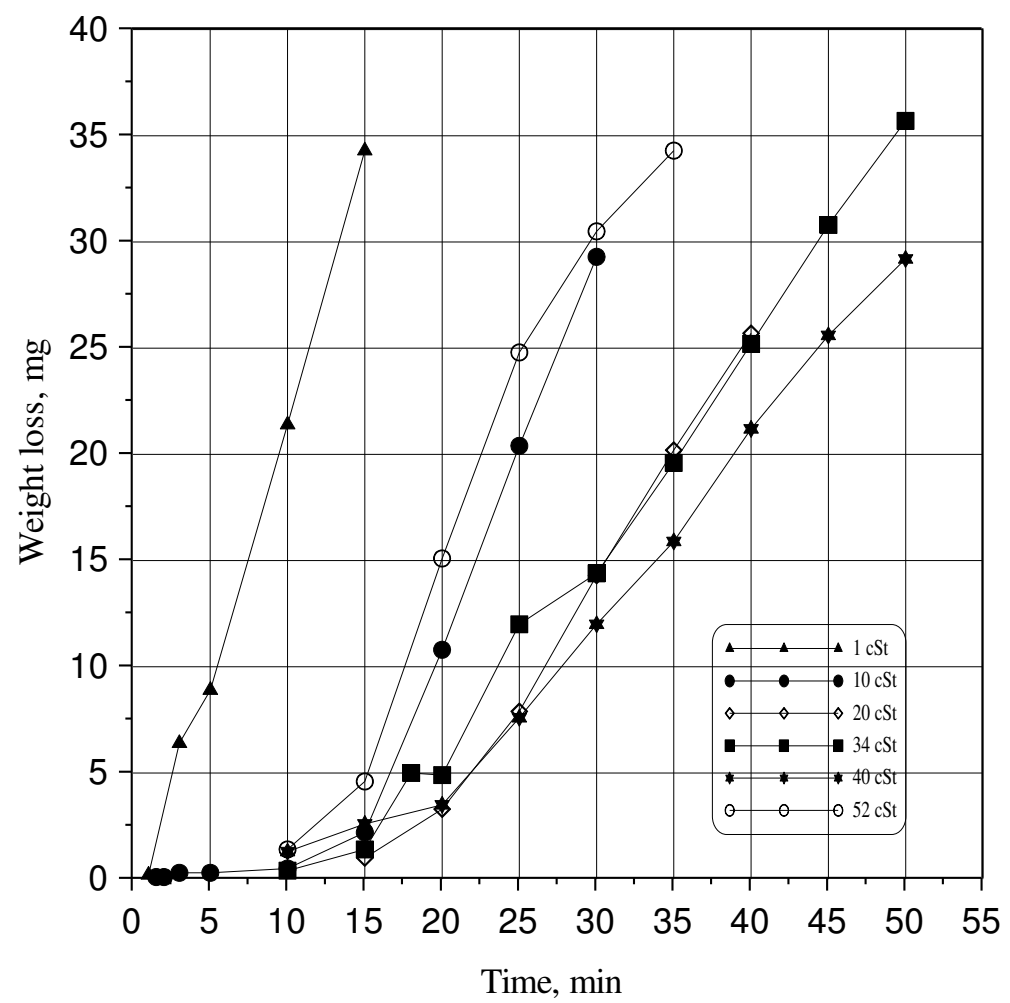

Fig.2 Weight loss of Al-99.92 specimens as function of test time for different viscosities

\subsection{Cavitation intensity versus viscosity}

It is reported in the literature that an increase in liquid viscosity causes, with all other fluid properties being held constant, a reduction in the number and size of cavitation bubbles. It is also reported that increase in liquid viscosity can reduce rate of bubble growth and collapse [19]. This will lead to a reduction in the cavitation intensity (no. of impact, intensity of impact) as the liquid viscosity increases. This is what observed for the reduction in the mass loss as viscosity increases (see Fig.2). Based on the particle characterization in this work and other results [13.15.16], the dominate failure mode in cavitation is fatigue failure. Under microscopic examination the most striking feature of many of the fracture faces caused by a fatigue crack is the presence of distinct line 
markings, parallel to each other and normal to the direction of crack growth. These lines are generally called striations. Each striation corresponds to one stress cycle, and the distance between striations is the amount that the crack has moved forward during that cycle $[20,21]$. The striation spacing is a measure of slow crack growth per stress cycle, and it may be constant for constant amplitude. However, striations may not form when the stress rate and the maximum stress are relatively large, leading to fast fatigue crack growth rate [21]. It can be seen from Fig. 3 and Fig. 5 for glycerol-water solution of $10 \mathrm{cs}$, the formation of striation spaces. However it can be observed from Figs. 3, 4 and 6 that no striations were formed in case of distilled water. This gives evidence that stress produced by cavitation decreases with the increases of viscosity.

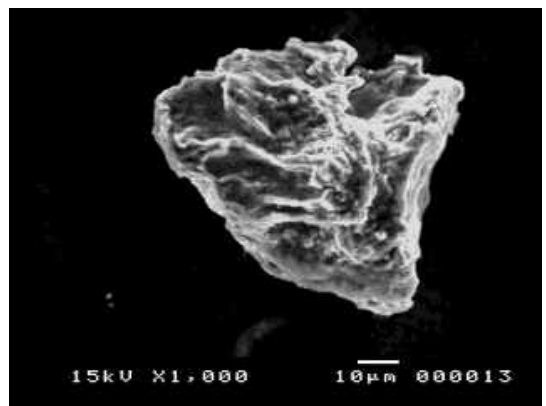

Distilled water, $1 \mathrm{cSt}$
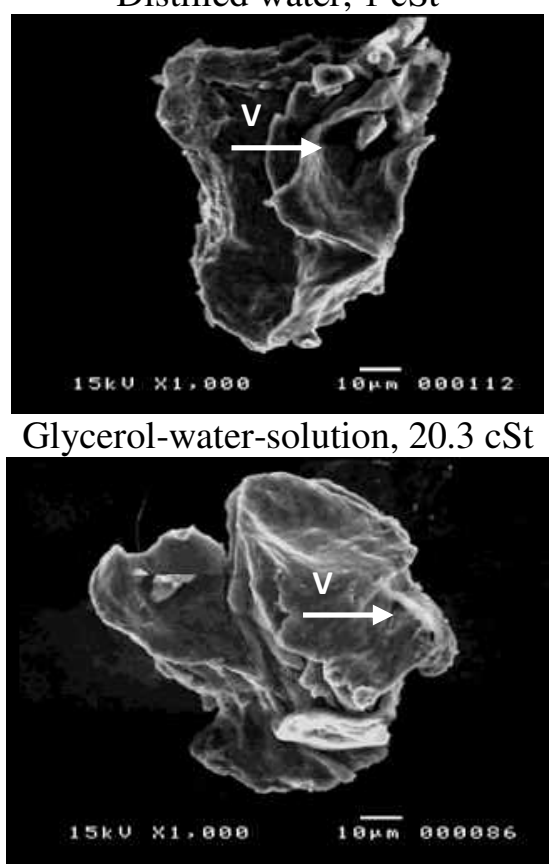

Glycerol-water-solution, $40.2 \mathrm{cSt}$

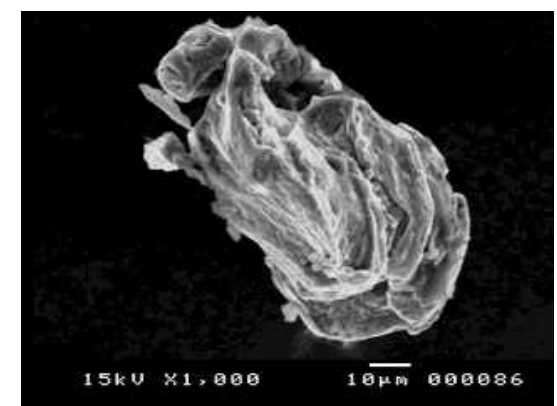

Glycerol-water-solution, $10 \mathrm{cSt}$

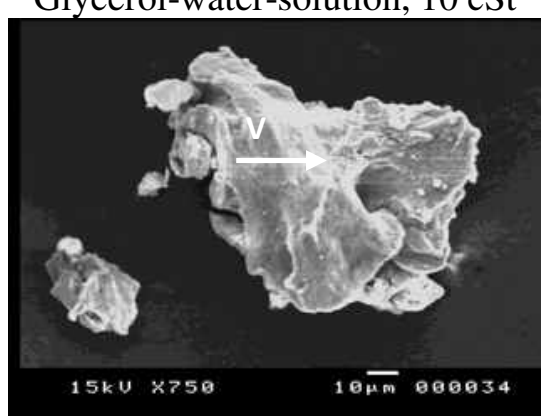

Glycerol-water-solution, $34.2 \mathrm{cSt}$

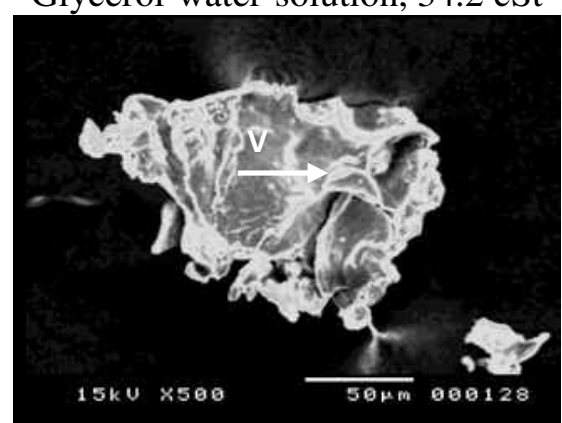

Glycerol-water-solution, $52.8 \mathrm{cSt}$

Fig. 3 Scanning electron photomicrographs of particles removed for Al-99.92 at different viscosities 


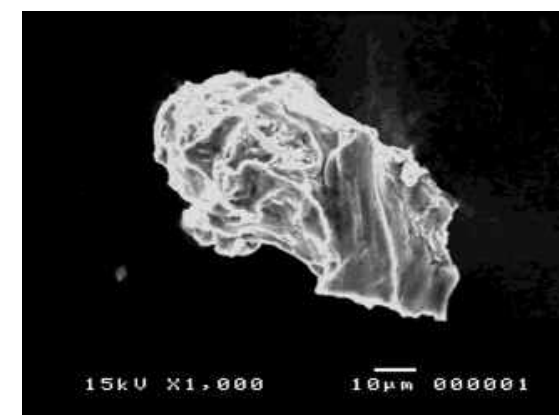

Glycerol-water-solution, $1 \mathrm{cSt}$

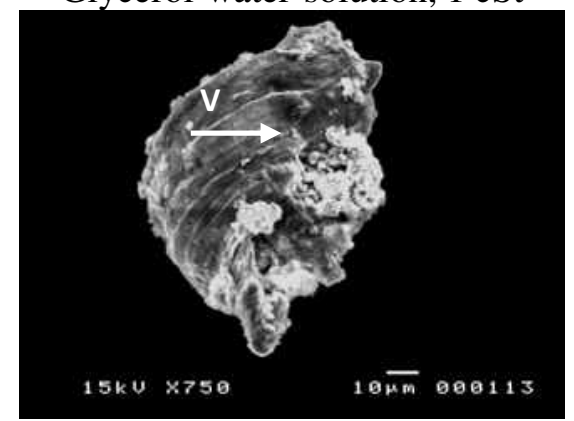

Glycerol-water-solution, $20.3 \mathrm{cSt}$

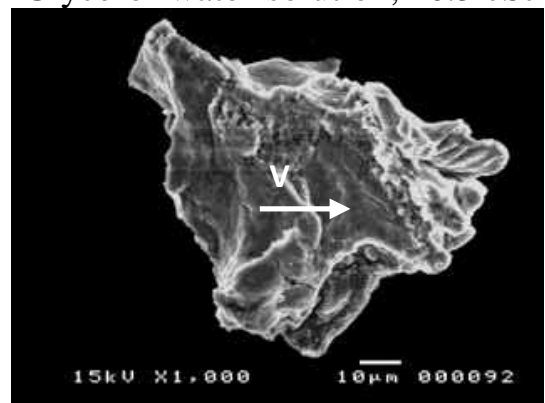

Glycerol-water-solution, $40.2 \mathrm{cSt}$

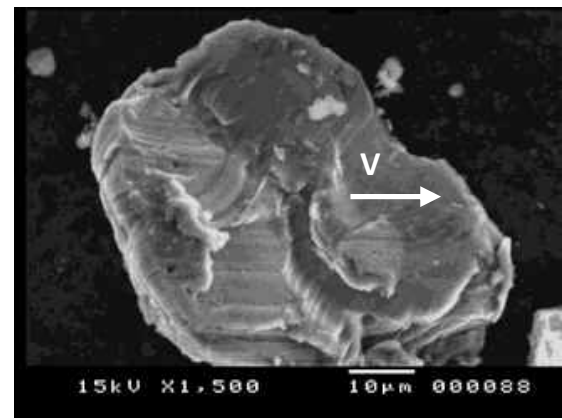

Glycerol-water-solution, $10 \mathrm{cSt}$

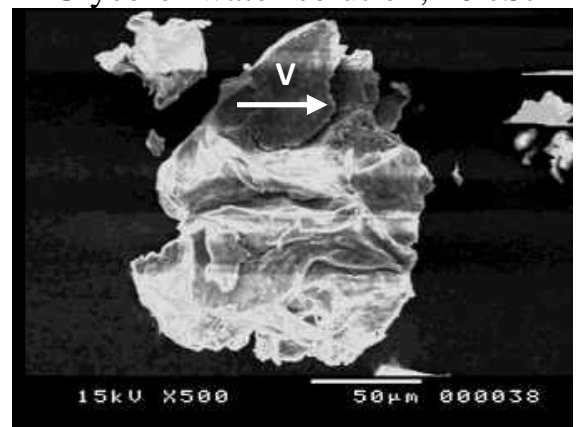

Glycerol-water-solution, $34.2 \mathrm{cSt}$

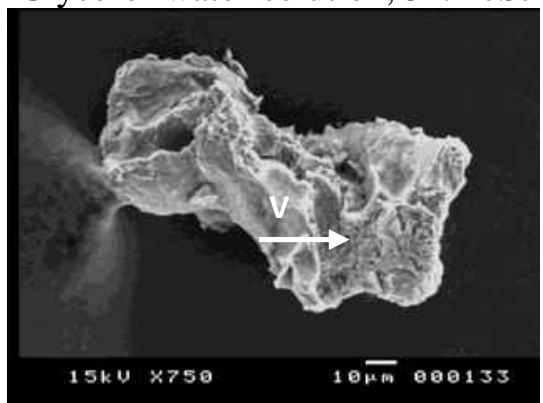

Glycerol-water-solution, $52.8 \mathrm{cSt}$

Fig.4 Scanning electron photomicrographs of particles removed for Al-99.92 at different viscosities

\section{CONCLUSION}

From the results and discussions presented above, the following conclusions can be drawn:

1. The morphology features of erosion particles formed in distilled water and glycerol-water solutions showed that the dominant failure mode in cavitation erosion is fatigues irrespective of viscosity.

2. Based on fatigue striations that were formed in glycerol-water mixtures and not in distilled water, it can be deduced that the formation of erosion particles is due to slow crack growth per stress cycle for viscous liquid and due to high stress rate for distilled water.

3. The cavitation intensity decreases with increasing the viscosity. 


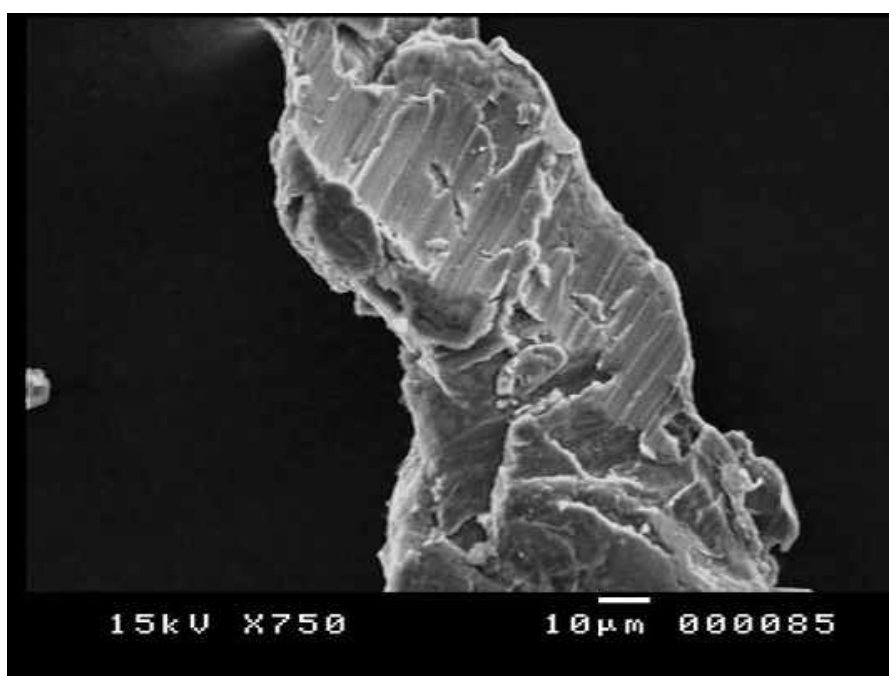

Fig.5 Particle surface showing fatigue striations for glycerol-water of $10 \mathrm{cSt}$

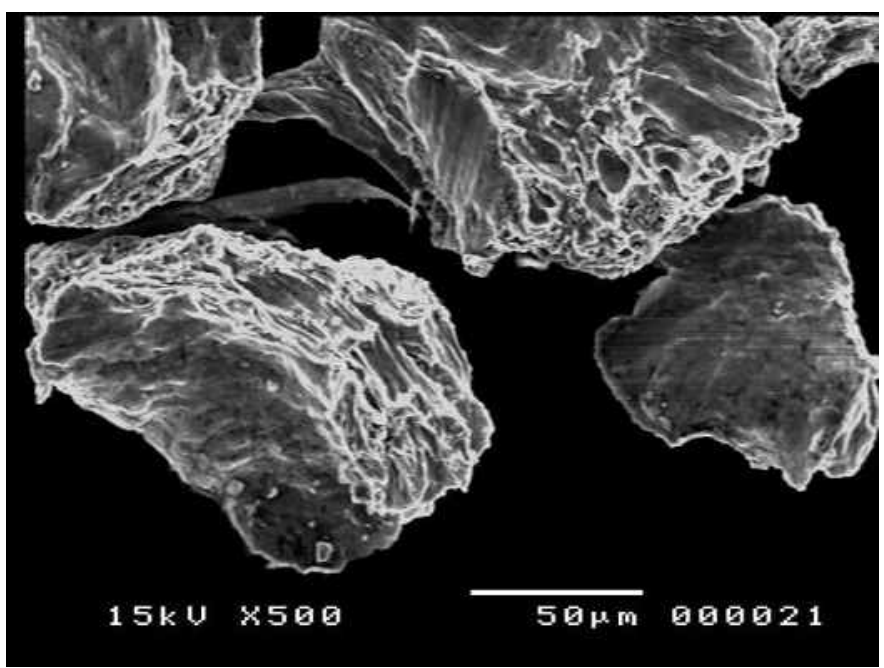

Fig.6 Particle surface showing crack propagation for distilled water of $1 \mathrm{cSt}$

\section{REFERENCES}

1- Knapp, R. T., Daily, J.W. and Hammitt, F. G. "Cavitation", McGraw-Hill, New York, 1970.

2- Hammitt, F. G. "Cavitation and multiphase flow phenomena", McGraw-Hill, New York, 1980.

3- Brennen, C. E. "Cavitation and bubble dynamics", Oxford: Oxford University Press, 1995.

4- Plesset, M. S. "Cavitation erosion in non aqueous liquids" Trans. ASME, J. Bas. Eng., 92, pp. 807- 814, 1970. 
5- Iwai, Y., Okada, T., and Maeda, R. "Cavitation damages of steel in water based fluids (Erosion in aqueous glycol solutions)", Proc. Jpn. Int. Trib. Conf., Nagoya, pp. 839- 844, 1990.

6- Urata, E. "Cavitation erosion in various fluids", Bath workshop on Power Transmission and Motion Control (Edited by C. R. Burrows and K. A. Edge), Professional Engineering Pub. LTD.(U.K.), pp.269-284 (Bath, 1998-9)

7- Liu, X., He, J., Lu, J. and Ni, X. "Effect of liquid viscosity on a liquid jet produced by the collapse of a laser- induced bubble near a rigid boundary", Jpn. J. Appl. Phys., 48, pp. 016504 -9, 2009.

8- ASTM G 32-06 "Standard test Method for cavitation erosion using vibratory apparatus", Annual book of ASTM standards. ASTM, Philadelphia, PA, 2006.

9- Vyas, B., and Preces, C. M. "Stress produced in a solid by cavitation", J. Appl. Phys., 47 (2), pp 5133- 5138, 1976.

10- Ahmed, S. M., Hokkirigawa, K., Kikuchi, K., Matsudaira, Y., Oshima, R., and Oba. R. "Marked surface-roughness effects on the development of micro fracture during the incubation period of vibratory cavitation erosion", in Proc. $3^{\text {rd }}$ JapanChina Joint Conf., Osaka, Japan, pp. 331- 338, 1990.

11- Ahmed, S. M., Hokkirigawa, K., Ito, Y., and Oba, R. "Scanning electron microscopy observation on the incubation period of vibratory cavitation erosion", Wear, 142, pp. 303 - 314, 1991.

12- Ahmed, S. M., Hokkirigawa, k, and Oba, R. "Fatigue of SUS 304 caused by vibratory cavitation erosion", Wear, 177, pp. 129- 137, 1994.

13- Saleh, B., Abouel-Kasem, A., Ezz El-Deen, A., and Ahmed, S. M. "Investigation of temperature effects on cavitation erosion behavior based on analysis of erosion particles", ASME, J. Tribology, Vol. 132, pp. 041601-1-041601-6, October 2010.

14- Ahmed, S. M. "Investigation of the temperature effects on induced impact pressure and cavitation erosion", wear, 218, pp. 119- 127, 1998.

15- Abouel-Kasem, A., and Ahmed, S.M. "Cavitation erosion mechanism based on analysis of erosion particles", ASME, J. Tribology, Vol. 130, pp. 031601-1-6 , 2008.

16- Abouel-Kasem, A., Emara, J. M., and Ahmed, S. M. "Characterizing cavitation erosion particles by analysis of SEM image", Trib. Int., 42, pp. 130-136, 2009.

17- Kuijpers, M. W. A. "Ultrsound-induced polymer reaction engineering in highpressure fluids", Ph. D. Thesis, Technische Universiteit Eindhoven, 2004.

18- Roylance, B. J., and Raanduvi, s. "The morphological attributes of wear particlestheir role in identifying wear mechanisms", wear, 175, 115- 121, 1994.

19- Poritsky, H. "The collapse or growth of a spherical bubble or cavity in a viscous fluid", The Proc. of the $1^{\text {st }}$ National congress on applied mechanics, ASME, N. Y., pp. 823- 825, 1952.

20- Pook, L. P. and Smith, R. A. "Theoretical background to elastic fracture mechanics, current status, fracture prospects", in: Smith (Ed.) Proc. Cambridge Univ. conf., 1979.

21- Kocanda, S. "Fatigue failure of metals", Wydawnieta Naukowd-Techniczne, Warsaw, Poland, 1978. 


\section{"تأثير لزوجة السائل علي تآكل التكهف مبنية علي تحليل الحبيات المتآكلة"}

في هذا البحث تم دراسة تأثير اللزوجة علي الحبيبات المتآكلة الناتجة من نآكل التكهف الناتج عن طريق جهاز الاهتزاز لعينات ثابتة من الألومونيوم النقي 99.92 في الماء المقطر وفي خليط من الجلسرين

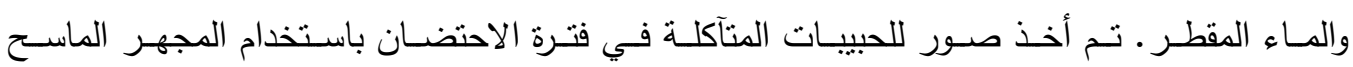
الإكتروني.وذلك بهدف دراسـة وتحليل هذه الحبيبات. فحص طبوغرافيا السطح كثفت أن الحبيبات المتآكلة تكونت عن طريق الكلل. الحبييات المتآكلة في الخليط من الجلسرين والماء المقطر تختلف عن تلك المتآكلة في الماء المقطر حيث أنه تشكلت حزازات الكلل علي أسطح الحبيبات المنآكلة في الخليط من الجلسرين والماء المقطر ولم تتشكل في الماء المقطر ـ لذلك فإن الإجهاد الناتج عن فقاعات التكهف يقل بزيادة اللزوجة. 